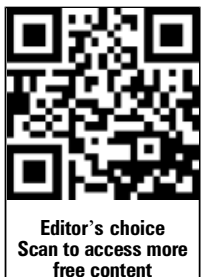

free content

- Additional material is published online only. To view please visit the journal online (http://dx.doi.org/10.1136/ oemed-2012-100963).

For numbered affiliations see end of article.

\section{Correspondence to}

Dr Dan Norbäck, Department of Medical Science, Uppsala University and Occupational and Environmental Medicine University Hospital, SE-751 85 Uppsala, Sweden; dan.norback@medsci.uu.se

Received 3 June 2012 Revised 20 November 2012 Accepted 9 January 2013 Published Online First 8 February 2013

\title{
Mould and dampness in dwelling places, and onset of asthma: the population-based cohort ECRHS
}

\author{
Dan Norbäck, ${ }^{1}$ Jan-Paul Zock, ${ }^{2,3,4}$ Estel Plana, ${ }^{2,3,4}$ Joachim Heinrich, ${ }^{5}$ Cecilie Svanes, ${ }^{6}$ \\ Jordi Sunyer, ${ }^{2,3,4,7}$ Nino Künzli, ${ }^{2,8}$ Simona Villani, ${ }^{9}$ Mario Olivieri, ${ }^{10}$ Argo Soon, ${ }^{11,12}$ \\ Deborah Jarvis ${ }^{13}$
}

ABSTRACT
Objectives To study new onset of adult asthma in

relation to dampness and moulds in dwelling places. Methods Totally, 7104 young adults from 13 countries who participated in the European Community Respiratory Health Survey (ECRHS I and II) who did not report respiratory symptoms or asthma at baseline were followed prospectively for 9 years. Asthma was assessed by questionnaire data on asthmatic symptoms and a positive metacholine challenge test at follow-up. Data on the current dwelling was collected at the beginning and at the end of the follow-up period by means of an interviewer-led questionnaire, and by inspection. Relative risks (RR) for new onset asthma were calculated with log-binomial models adjusted for age, sex, smoking and study centre.

Results There was an excess of new asthma in subjects in homes with reports on water damage (RR 1.46; $95 \%$ $\mathrm{Cl} 1.09$ to 1.94$)$ and indoor moulds ( $\mathrm{RR}=1.30 ; 95 \% \mathrm{Cl}$ 1.00 to 1.68) at baseline. A dose-response effect was observed. The effect was stronger in those with multisensitisation and in those sensitised to moulds. Observed damp spots were related to new asthma $(R R=1.49 ; 95 \% \mathrm{Cl} 1.00$ to 2.22). The populationattributable risk was 3-10\% for reported, and 3-14\% for observed dampness/moulds.

Conclusions Dampness and mould are common in dwellings, and contribute to asthma incidence in adults.

Building dampness and indoor mould growth are common in many countries, both in dwellings and other buildings, and reviews have concluded that there is evidence for an association between damp housing conditions and respiratory symptoms in adults. ${ }^{1-4}$ One meta-analysis concluded that building dampness and indoor moulds are associated with approximately $30-50 \%$ increases in a variety of respiratory and asthma-related health outcomes. ${ }^{4}$ These conclusions are mainly based on prevalence studies, as only few longitudinal studies on adult onset of asthma in relation to dampness and moulds are available. ${ }^{5} 6$ Moreover, most studies are based only on questionnaire data, few have included clinical data or independent observation of dampness or moulds. The biological mechanisms behind the observed associations remains unclear. There is a complex exposure pattern related to building dampness, including house dust mite allergens, ${ }^{7}$ microbial compounds from moulds ${ }^{8}$ and bacteria, ${ }^{9}$ chemical emissions from degradation of

\section{What this paper adds}

Several studies have shown associations between dampness and indoor moulds in dwellings, and asthma and respiratory symptoms. Most of these are cross-sectional studies.

- This study adds knowledge on onset of asthma in relation to dampness and moulds in dwellings in a large cohort study in adults. It includes self-reported as well as observed signs of dampness and moulds.

- The results implicate a clear need for improvements of housing conditions in Europe in order to reduce the dampness-related exposure.

building materials ${ }^{10}$ as well as volatile organic compounds of microbial origin. ${ }^{11}$

The European Community Respiratory Health Survey (ECRHS) is an international multicentre epidemiological cohort study on asthma, covering 48 centres in 23 countries, started in $1990-1995 .{ }^{12} 13$ A cross-sectional analysis of data from ECRHS showed that mould exposure was associated with increased prevalence of asthma symptoms and bronchial hyperresponsiveness (BHR). The association was homogenous among centres, and was stronger in subjects sensitised to moulds. ${ }^{7}$ From 1998 to 2002, a follow-up of the cohort was carried out (ECHRS II). ${ }^{14}$ We studied lung function decline in the cohort in relation to dampness and moulds in ECRHS II. ${ }^{15}$ This study aims to investigate new onset of asthma in the ECRHS II in relation to self-reported as well as observed building dampness and indoor moulds in the dwelling, and estimate attributable risks. Moreover, new onset was studied in relation to some other building characteristics.

\section{METHODS}

Study population and procedures

Each centre covers a source population of approximately 150000 inhabitants within a defined geographical and administrative area. The full research protocol can be found at http://www.ecrhs.org. Ethics approval was obtained for each centre from the ethical committee, and written consent was obtained from each participant. We included 
subjects from the random sample who completed the main medical questionnaires both in ECRHS I and ECRHS II (19982002). Totally, 15716 took part in the random sample of the ECRHS I, and 8770 completed both the medical and the indoor questionnaires in ECRHS II. Two centres (Cardiff, Geleen) omitted the indoor environment questions and were excluded, leaving 25 centres located in 11 countries in Europe and two outside Europe (Melbourne in Australia and Portland in USA). New onset asthma at the follow-up was studied, excluding subjects $(n=1666)$ having wheeze without a cold, nocturnal attack of shortness of breath in the last 12 months, or a history of asthma at baseline (ECRHS I), leaving 7104 subjects to be followed prospectively. Strong exclusion criteria were chosen since non-differential disease misclassification may bias incidence risk ratios away from the null. ${ }^{16} \mathrm{New}$ onset asthma was defined as answering 'yes' on at least one of three questions on current attacks of asthma (last 12 months), current asthma medication and nocturnal attack of shortness of breath in the last 12 months in ECRHS II. Additionally, we tested BHR in ECRHS II. BHR was defined as a fall of forced expiratory volume in the first second $\left(\mathrm{FEV}_{1}\right)$ of $20 \%$ from the highest $\mathrm{FEV}_{1}$, associated with a methacholine dose of $1 \mathrm{mg}$ or less. For a more specific definition of asthma, we combined reports of asthma and BHR at ECRHS II.

Information on age, sex and smoking habits was collected from the interviewer-led questionnaire. Current smoker was defined as subject reporting actual smoking in the interview, or ceasing smoking less than a year ago. Smoking was defined according to ECRHS II. Subjects giving inconsistent answers on smoking habits at ECRHS I and II $(n=78)$ were included in the statistical models with a separate code, as an extra dummy variable. Specific serum $\mathrm{IgE}$ levels against cat and timothy grass, the mould Cladosporium herbarium and the house dust mite Dermatophagoides pteronyssinus were determined by using the Pharmacia CAP System (Pharmacia Diagnostics, Uppsala, Sweden), both in ECRHS I and II. Sensitisation was defined as a specific IgE level greater than $0.35 \mathrm{kU} / \mathrm{l}$. In addition, skin prick test to the mould Alternaria alternata was performed in ECRHS I, only.

Information on housing characteristics of the current dwelling was obtained from interviewer-led questionnaires performed in the beginning and in the end of the follow-up period. The current dwelling was defined as the dwelling where the subject lived when the interview took place. One question asked if the participant had moved during the follow-up period. Building data included building age, type of building, type of heating system, presence of double glazing, and type of floor cover in the bedroom and the living room. The living room was defined as the room used most at home during the days. There were questions on any history of water damage in the dwelling (broken pipes, leaks, flooding), as well as water leakage the last 12 months. Moreover, there was a question on any history of mould or mildew on any surface inside the dwelling, the location of the mould growth, and indoor mould or mildew during the last 12 months. All these questions were asked in the same way in ECRHS I and ECRHS II. ECRHS II contained one additional question on wet or damp spots on indoor surfaces other than the basement (eg, on walls, wall paper, ceilings or carpets) the last 12 months.

Initially, we analysed for four exposure variables reported at baseline for the dwelling they lived in at that time: any water damage during the last 12 months, any mould growth in the last 12 months, any mould growth in the bedroom and any mould growth in the living room. Additionally, the same exposure variables were analysed for combined exposure data from ECRHS I and ECRHS II (ever exposed vs never exposed). In addition, associations for reports on any damp spots in the last 12 months, available only in ECRHS II, were analysed. In order to detect any dose-response relationships, two exposure scores were created. The dampness score (0-5) included number of yes answers on ever dampness (ECRHS I or II), 12 months dampness (I or II), or damp spots (ECRHS II). The mould score (0-4) included number of yes answers on ever moulds (ECRHS I or II), and 12 months on moulds (I or II). Finally, the number of rooms with reported mould growth either at ECRHS I or II was counted.

Totally, 22 centres participated in an additional indoor environmental study ('The Indoor Protocol'), including a home visit, building inspection and collecting of dust samples from the bedroom mattress in approximately 200 homes in each centre. ${ }^{17}$ Data on observed dampness and indoor moulds was obtained from 2602 homes from the random sample free of asthma at baseline. The indoor protocol contained eight questions on dampness: three for dampness, three for moulds and two for window condensation. These were grouped into three categories.

\section{Observed dampness}

Are there any damp patches on the walls or ceilings of the living room, bedroom, bathroom? (Three separate questions filled in by the inspector).

\section{Observed mould}

Is there any mould or mildew on the walls and ceilings in the living room, bedroom, bathroom? (Three separate questions filled in by the inspector).

\section{Window condensation}

Do you get condensation on your living room/bedroom window especially in the morning in the winter? (Two separate questions asked to the subject at the home visit).

\section{Statistical analysis}

Adjusted relative risks (RR) for asthma were calculated, using log-binomial models, adjusting for sex, age, smoking status and study centre. RRs were first analysed on pooled data from all 27 centres, adjusting for centre. We did a meta-analysis to test heterogeneity by centre, using standard methods for random-effects meta-analysis. ${ }^{18}$ In the meta-analysis, centres with too low a number of subjects were omitted. For estimation of population-attributable fraction (PAF) we first applied Poisson regression with robust estimation of error to establish RR, and then calculated attributable risks. ${ }^{19}$ The statistical analysis was performed using Stata V.10.0 (Stata Corporation, College Station, Texas, USA).

\section{RESULTS}

Mean follow-up time was 8.7 years (range 5.9-11.7 years). In the cohort, the prevalence of active smoking had decreased from $31.9 \%$ to $27.1 \%$. Sensitisation to common allergens, defined as a positive IgE to cat and timothy grass, house dust mites or the mould, C herbarium, was unchanged $(26.2 \%$ at ECRHS I and $25.0 \%$ at ECRHS II). Totally, there were 355 cases of new onset asthma, the most common symptom was new onset of nocturnal attacks of shortness of breath. Symptoms of asthma and shortness of breath increased in a similar way in both sexes. Relatively few cases $(n=56)$ had BHR (table 1).

To study possible selection bias, we compared reporting of asthma and exposure at ECRHS I among participants $(n=8770)$ 
Table 1 Respiratory health characteristics of the study population $(n=7104)$

\begin{tabular}{|c|c|c|c|c|}
\hline & \multicolumn{2}{|c|}{ ECRHS I } & \multicolumn{2}{|c|}{ ECRHS II } \\
\hline & $\mathbf{n}$ & $\%$ & $\mathbf{n}$ & $\%$ \\
\hline \multicolumn{5}{|l|}{ Smoking status } \\
\hline Never & 3267 & 46.0 & 3094 & 43.6 \\
\hline Ex & 1569 & 22.1 & 2010 & 28.3 \\
\hline Current & 2265 & 31.9 & 1922 & 27.1 \\
\hline New onset asthma* & 0 & 0.0 & 355 & 5.0 \\
\hline Current asthma attacks & 0 & 0.0 & 98 & 1.4 \\
\hline Current asthma medication & 0 & 0.0 & 81 & 1.2 \\
\hline Nocturnal attacks of shortness of breath & 0 & 0.0 & 254 & 3.6 \\
\hline Parental asthma & 696 & 10.5 & NA & NA \\
\hline Bronchial hyper-responsiveness (BHR) & 431 & 7.8 & 440 & 9.7 \\
\hline New onset asthma combined with positive BHR† & NA & NA & 56 & 1.4 \\
\hline Positive IgE to Cladosporium herbarum (mould) & 171 & 2.9 & 41 & 0.7 \\
\hline Prick test positivity to Altenaria alternata (mould) & 501 & 8.5 & NA & NA \\
\hline Positive IgE to house dust mite (der p1) & 839 & 14.2 & 756 & 13.6 \\
\hline Positive lgE to cat or timothy grass & 409 & 6.9 & 373 & 6.7 \\
\hline No sensitisation $\ddagger$ & 4349 & 73.8 & 4161 & 75.0 \\
\hline
\end{tabular}

and non-participants $(n=6946)$ in the follow-up. Prevalent asthma (attacks of asthma and/or nocturnal attack of shortness of breath in the last 12 months and/or current asthma medication) in ECRHS I was $7.6 \%$ in participants and $9.4 \%$ in nonparticipants $(p<0.001)$. However, the reports on exposure at baseline did not differ. The prevalence of self-reported water damage in the last 12 months at ECRHS I was $11.7 \%$ in participants and $12.8 \%$ in non-participants in the follow-up $(p=0.50)$. The prevalence of self-reported moulds in the last 12 months at ECRHS I was $19.7 \%$ in participants and $20.1 \%$ in nonparticipants $(p=0.59)$. The prevalence of self-reported moulds in the bedroom at baseline was $11.9 \%$ in participants and $12.4 \%$ in non-participants $(p=0.40)$. The prevalence of selfreported moulds in the living room at ECRHS I was $6.2 \%$ in participants and $6.7 \%$ in non-participants $(p=0.27)$.

Self-reported water damage, damp spots and indoor mould growth in the current dwelling was common at both surveys. There was a slight but significant decrease of dampness and moulds during the follow-up. Self-reported moulds were most common in the bathroom and the bedroom, and least common in the kitchen. Totally, $49.7 \%$ reported water damage either at ECRHS I or II (damp score $>0$ ), and $41.7 \%$ reported indoor mould growth (damp score $>0$ ). The prevalence of observed dampness and moulds were lower, but window condensation in winter was common (table 2).

First, we analysed RR for new onset asthma in relation to exposure at baseline. RR for onset of asthma was increased among those reporting water damage in the last 12 months and moulds in the last 12 months. The population-attributable fractions for selfreported dampness and moulds were between $2 \%$ and $5 \%$ for asthma, and $3 \%$ and $6 \%$ for asthma+BHR. Then we analysed associations for those ever exposed (ever vs never). RR for new onset asthma was increased among subjects reporting water damage in the last 12 months, damp spots in the last 12 months,
Table 2 Dampness characteristics of the current dwelling of subjects in the cohort, reported at ECRHS I and ECRHS II

\begin{tabular}{|c|c|c|c|c|}
\hline & & $\begin{array}{l}\text { ECRHS I } \\
\text { prev (\%) }\end{array}$ & $\begin{array}{l}\text { ECRHS II } \\
\text { prev (\%) }\end{array}$ & $\begin{array}{l}\text { Mc Nemar's } \\
\text { p value }\end{array}$ \\
\hline Self-reported & $(n=7104)$ & & & \\
\hline \multirow[t]{2}{*}{$\begin{array}{c}\text { Water } \\
\text { damage }\end{array}$} & $\begin{array}{l}\text { Ever*, any } \\
\text { placet }\end{array}$ & 26.7 & 27.9 & 0.118 \\
\hline & $\begin{array}{l}12 \text { months, } \\
\text { any placet }\end{array}$ & 11.2 & 10.2 & 0.054 \\
\hline Damp spots & $\begin{array}{l}12 \text { months, } \\
\text { any placet }\end{array}$ & NA & 19.7 & \\
\hline \multirow[t]{2}{*}{ Mould } & $\begin{array}{l}\text { Ever, any } \\
\text { placet }\end{array}$ & 29.7 & 24.8 & $<0.001$ \\
\hline & $\begin{array}{l}12 \text { months, } \\
\text { any placet }\end{array}$ & 18.6 & 16.7 & $<0.001$ \\
\hline Observed & $(n=2602)$ & & & \\
\hline Damp spots & Any placet & NA & 18.2 & \\
\hline $\begin{array}{l}\text { Visible } \\
\text { moulds }\end{array}$ & Any placet & NA & 13.6 & \\
\hline $\begin{array}{l}\quad \text { Reported } \\
\text { window } \\
\text { condensation } \\
\text { in winter in } \\
\text { any room }\end{array}$ & & NA & 32.7 & \\
\hline
\end{tabular}

and indoor moulds in the last 12 months. The associations were most pronounced for moulds in the bedroom and in the living room. New onset asthma combined with BHR was increased for self-reported moulds in the living room. The PAFs for selfreported dampness and moulds were between 3\% and 10\% for new onset asthma, and 3\% and $8 \%$ for asthma+BHR (table 3 ).

As a next step, we stratified for gender. The risk estimates for new onset asthma in relation to being ever exposed to dampness and moulds were similar in men and women, with no significant sex-interaction except for moulds in the living room $(p=0.03$ for interaction) (see online supplementary table E1). The RR for new onset asthma in relation to self-reported moulds in the living room was 0.89 (95\% CI 0.51 to 1.52 ) for men and 2.02 (95\% CI 1.40 to 2.92) for women. When stratifying for smoking, we found no interaction for current smoking, but lower risk estimates for water damage during the last 12 months $(p=0.09)$, and higher risk estimates for mould score $>0$ $(p=0.03)$ and moulds in the bedroom $(p=0.06)$ in ex-smokers as compared with never smokers (data not shown). Additionally, we stratified the material with respect to sensitisation at baseline, analysing ever exposed versus never exposed. Among subjects with no sensitisation $(n=3329)$ there were associations between new onset asthma and self-reported water damage in the last 12 months ( $R R=1.07 ; 95 \% \mathrm{CI} 1.07$ to 2.39$)$ and self-reported mould in the last 12 months $(\mathrm{RR}=1.57$; $95 \%$ CI 1.09 to 2.27$)$. Among subjects with sensitisation to cat and timothy grass, but not to house dust mites or mould $(n=1303)$, there were associations between new onset asthma and self-reported mould in the living room in the last 12 months $(\mathrm{RR}=2.05 ; 95 \%$ CI 1.17 to 3.61$)$. Among subject with sensitisation to house dust mites but not to mould $(n=1064)$, there were associations between new onset asthma and self-reported mould in the bedroom in the last 12 months $(\mathrm{RR}=1.87 ; 95 \% \mathrm{CI} 1.12$ to 3.10$)$. Among subjects sensitised to mould at baseline (C herbarium or A alternata) $(\mathrm{n}=339)$, 
Table 3 New onset of asthma in relation to self-reported dampness and moulds at baseline and at baseline or follow-up (ever vs never exposed)

\begin{tabular}{|c|c|c|c|c|c|c|c|}
\hline & \multirow[b]{3}{*}{ Exposed (\%) } & \multirow{2}{*}{\multicolumn{3}{|c|}{$\begin{array}{l}\text { Asthma } \\
(n=6984)\end{array}$}} & \multicolumn{3}{|c|}{ Asthma and BHR } \\
\hline & & & & & \multicolumn{3}{|l|}{$(n=6615)$} \\
\hline & & Adjusted RR* & $95 \% \mathrm{Cl}$ & PAF (\%) & Adjusted RR* & $95 \% \mathrm{Cl}$ & PAF (\%) \\
\hline \multicolumn{8}{|l|}{ Exposed at baseline (ECRHS I) } \\
\hline Water damage in last 12 months & 11.3 & 1.46 & (1.09 to 1.94$)$ & 4.8 & 1.48 & (0.71 to 3.07$)$ & 5.7 \\
\hline Mould in last 12 months & 18.6 & 1.30 & (1.00 to 1.68$)$ & 5.1 & 1.16 & (0.61 to 2.22$)$ & 3.0 \\
\hline Mould in bedroom (ever) & 11.4 & 1.08 & (0.79 to 1.48$)$ & 1.0 & 0.97 & $(0.43$ to 2.16$)$ & - \\
\hline Mould in living room (ever) & 6.1 & 1.34 & (0.91 to 1.97$)$ & 2.0 & 1.50 & (0.61 to 3.69$)$ & 2.7 \\
\hline \multicolumn{8}{|c|}{ Ever exposed (ECRHS I and/or ECRHS II) versus never exposed } \\
\hline Water damage in last 12 months & 19.1 & 1.29 & (1.00 to 1.66$)$ & 5.1 & 1.22 & (0.63 to 2.36$)$ & 4.3 \\
\hline Mould in the last 12 months & 28.9 & 1.36 & $(1.08$ to 1.70$)$ & 10.3 & 1.23 & (0.70 to 2.19$)$ & 7.9 \\
\hline Mould in bedroom (ever) & 18.4 & 1.43 & (1.12 to 1.84$)$ & 4.9 & 1.14 & (0.57 to 2.26$)$ & 2.5 \\
\hline Mould in living room (ever) & 10.0 & 1.48 & (1.10 to 2.01$)$ & 3.4 & 2.24 & (1.15 to 4.36$)$ & 8.0 \\
\hline Damp spots, last 12 monthst & 19.7 & 1.28 & (1.00 to 1.65$)$ & 5.3 & 0.96 & (0.49 to 1.89$)$ & - \\
\hline
\end{tabular}

there were associations between new onset asthma and selfreported water damage in the last 12 months $(\mathrm{RR}=4.57 ; 95 \% \mathrm{CI}$ 2.10 to 9.94$)$ and self-reported mould in the living room $(\mathrm{RR}=4.38 ; 95 \% \mathrm{CI} 1.80$ to 10.62 ) (see online supplementary table E2).

As a next step, heterogeneity between centres was tested, comparing those reporting being ever exposed with those never exposed. Meta-analysis of new onset asthma in relation to water damage or damp spots in the last 12 months, did not reveal any heterogeneity between centres $(p=0.75$ and 0.81 , respectively), but some heterogeneity was found for indoor moulds in the last 12 months $(p=0.09)$ (see online supplementary figures E1-E3).

In order to detect any dose-response relationship, associations were analysed for the dampness score, the mould score, and number of rooms with reported mould growth. There was a significant dose-response for dampness score and new onset asthma, and a significant dose-response for the mould score and new onset asthma. Moreover, there was an association between the number of rooms with mould growth and new onset asthma $(p=0.011)$, and a borderline association $(p=0.057)$ for new onset asthma with BHR (table 4). The two scales had a weak correlation (Spearmans $\mathrm{r}$ 0.35), and were independent scales $(\mathrm{p}<0.001)$ but with some overlap. Totally, 27\% had both the mould score $>0$ and the dampness score $>0$.

The RR for new onset asthma was increased in homes with any damp spots (in a bedroom, living room or bathroom) observed at the home inspection (table 5). The PAFs for observed dampness and moulds were between $2 \%$ and $8 \%$ for asthma, and $6 \%$ and $4 \%$ for asthma+BHR. There were no associations between new onset asthma and observed mould.

Totally, 49.3\% had moved to another home during the follow-up period. The proportion of new onset asthma did not

Table 4 New onset of asthma in relation to self-reported dampness and mould scores and number of rooms with mould, ECRHS I and II

\begin{tabular}{|c|c|c|c|c|c|c|c|}
\hline & \multirow[b]{2}{*}{ n \% } & \multicolumn{2}{|l|}{ Asthma } & \multirow[b]{2}{*}{ p Value } & \multicolumn{2}{|c|}{ Asthma with BHR } & \multirow[b]{2}{*}{ p Value } \\
\hline & & Adjusted RR* & $95 \% \mathrm{Cl}$ & & Adjusted RR* & $95 \% \mathrm{Cl}$ & \\
\hline Damp score & $n=5870$ & & & & & & \\
\hline 0 & 50.3 & 1 & (ref.) & & 1 & (ref.) & \\
\hline $1-2$ & 37.8 & 1.14 & (0.90 to 1.45$)$ & 0.284 & 0.83 & (0.44 to 1.56$)$ & 0.571 \\
\hline $3-5$ & 11.9 & 1.28 & (0.91 to 1.81$)$ & 0.150 & 1.26 & (0.55 to 2.87 ) & 0.580 \\
\hline Trend & & 1.09 & (1.00 to 1.20$)$ & 0.047 & 1.03 & (0.81 to 1.30$)$ & 0.835 \\
\hline Mould score & $n=6698$ & & & & & & \\
\hline 0 & 58.4 & 1 & (ref.) & & 1 & (ref.) & \\
\hline $1-2$ & 30.8 & 1.05 & (0.82 to 1.33 ) & 0.722 & 0.62 & (0.31 to 1.25$)$ & 0.181 \\
\hline $3-4$ & 10.8 & 1.73 & (1.27 to 2.37 ) & 0.001 & 1.83 & (0.88 to 3.80$)$ & 0.105 \\
\hline Trend & & 1.12 & (1.03 to 1.22$)$ & 0.007 & 1.08 & (0.87 to 1.34$)$ & 0.477 \\
\hline Rooms with mould (n) & $n=6776$ & & & & & & \\
\hline 0 & 76.0 & 1 & (ref.) & & 1 & (ref.) & \\
\hline 1 & 21.2 & 1.30 & (1.02 to 1.66$)$ & 0.035 & 1.24 & (0.66 to 2.32 ) & 0.511 \\
\hline $2-3$ & 2.8 & 1.43 & (0.83 to 2.48$)$ & 0.196 & 2.41 & (0.82 to 7.05$)$ & 0.108 \\
\hline Dose-response & & 1.17 & (1.04 to 1.32$)$ & 0.011 & 1.31 & (0.99 to 1.74$)$ & 0.057 \\
\hline
\end{tabular}

${ }^{*}$ Adjusted for age, sex, smoking status and centre. $\mathrm{RR}$, relative risks. 
Table 5 New onset of asthma in relation to observed dampness, moulds and window condensation

\begin{tabular}{|c|c|c|c|c|c|c|c|}
\hline & \multirow{3}{*}{$\begin{array}{l}\text { ECRHS II } \\
\text { Exposed (\%) }\end{array}$} & \multirow{2}{*}{\multicolumn{2}{|c|}{$\begin{array}{l}\text { Asthma } \\
(n=2484)\end{array}$}} & \multirow[b]{3}{*}{ PAF (\%) } & \multicolumn{2}{|c|}{ Asthma and BHR } & \multirow[b]{3}{*}{$\operatorname{PAF}(\%)$} \\
\hline & & & & & \multicolumn{2}{|l|}{$(n=1557)$} & \\
\hline & & Adjusted RR* & $95 \% \mathrm{Cl}$ & & Adjusted RR* & $95 \% \mathrm{Cl}$ & \\
\hline Any damp spots & 18.3 & 1.49 & (1.00 to 2.22$)$ & 8.20 & 1.88 & (0.84 to 4.22$)$ & 14.40 \\
\hline Damp spots in bedroom & 7.0 & 1.63 & (0.95 to 2.78$)$ & 4.10 & 2.57 & (0.91 to 7.27 ) & 8.70 \\
\hline Damp spots in living room & 5.8 & 0.98 & (0.46 to 2.07 ) & - & NA & NA & - \\
\hline Damp spots in bathroom & 9.8 & 1.21 & (0.72 to 2.03 ) & 2.21 & 1.62 & (0.61 to 4.30$)$ & 6.93 \\
\hline Any visible mould & 13.6 & 1.15 & (0.71 to 1.85$)$ & 1.90 & 1.74 & (0.68 to 4.45$)$ & 9.50 \\
\hline Visible mould in bedroom & 4.9 & 1.56 & (0.83 to 2.92$)$ & 2.80 & 2.51 & (0.61 to 10.40$)$ & 6.40 \\
\hline Mould spots in living room & 2.9 & 0.99 & (0.37 to 2.65$)$ & - & 0.97 & (0.12 to 7.56$)$ & - \\
\hline Mould spots in bathroom & 9.2 & 0.79 & $(0.41$ to 1.51$)$ & - & 1.14 & (0.34 to 3.86$)$ & 1.09 \\
\hline Reported window condensation in winter in any room & 32.7 & 1.07 & (0.75 to 1.53$)$ & 2.00 & 1.43 & (0.67 to 3.07$)$ & 13.20 \\
\hline
\end{tabular}

differ between those moving and not moving (data not shown). Moreover, there were no differences in reports on dampness and moulds between those participating and not participating in the home inspections (data not shown). Finally, we compared RR for new onset asthma in relation to self-reported dampness and moulds (ever vs never exposed) in those moving and not moving to another home during the follow-up. RRs for new onset asthma were similar in movers and non-movers for all types of exposure with overlapping CIs. Among those living in the same home, there was an association between new onset asthma and self-reported mould in the bedroom $(\mathrm{RR}=1.61$; $95 \%$ CI 1.13 to 2.30 ) and self-reported damp spots in the last 12 months ( $\mathrm{RR}=1.49$; 95\% CI 1.06 to 2.09). Among those moving to another home, there was an association between new onset asthma and self-reported water damage ( $\mathrm{RR}=1.48 ; 96 \%$ CI 1.05 to 2.09). When analysing associations for new onset asthma combined with BHR, those staying in the same home had always higher RR as compared with those moving. There were significant associations for self-reported mould in the bedroom $(\mathrm{RR}=2.64 ; 95 \% \mathrm{CI} 1.10$ to 6.33$)$ and self-reported mould in the living room $(\mathrm{RR}=3.79 ; 95 \% \mathrm{CI} 1.64$ to 8.73$)$ among non-movers, while movers had no significant associations for any type of exposure (see online supplementary table E3).

\section{DISCUSSION}

Our longitudinal study indicated that dampness and moulds can increase the risk for adult new onset asthma. Associations were found both for self-reported and observed exposure. Moreover, there were associations between new onset asthma and the dampness score, mould score and number of rooms with indoor moulds, indicating a dose-response effect. Similar associations, but higher population-attributable risk, was found when considering exposure data from both ECRHS I and ECRHS II (ever vs never exposed). The similarities between these different analysis makes recall bias less probable.

There are certain limitations of the study. Exposure to moulds and dampness was assessed by questionnaire as well as independent observation in the current home of a random subsample. Response bias could have influenced the associations for self-reported exposure, but is less likely to influence associations with observed dampness and indoor mould. However, associations were found for water damage and mould at baseline which is a strength, because the exposure is measured before new onset of asthma. We did not adjust for season, but the recall period for both symptoms and exposure was either 12 months or ever (ever for exposure in specified rooms). Another limitation is that we only ask for dampness and mould in the current home, and about half the subjects had moved to another home during the follow-up period. Moreover, we have no information as to when the new onset asthma occurred, so in some cases, the new onset could have occurred before the exposure. This limitation would most likely lead to non-differential misclassification.

The study covered different climate zones, and the associations were consistent across areas. It is possible that the international variation of asthma prevalence partly could be explained by variation of this exposure. An ecological analysis has reported a higher prevalence of asthma at oceanic climate. ${ }^{20}$ The prevalence of self-reported dampness and indoor moulds were high in ECRHS I as well as ECRHS II, indicating only minor improvement of the housing conditions during the $1990 \mathrm{~s}$ in Europe. There were different patterns of associations for mould growth as compared with water leakage, which indicates that there could be different pathways for the effects of building dampness on asthma. Increased water content in building materials or on indoor surfaces can lead to visible mould growth, as well as increase of house dust mites, hidden microbial growth inside the building, and chemical degradation of building materials without microbial growth. ${ }^{10}$

In the current follow-up study, we found significant associations between dampness and mould and new onset asthma, which is in agreement with a previous cross-sectional analysis within ECRHS I. ${ }^{7}$ In another cohort study in preschool children in the Swedish DBH study, there were no associations between dampness/moulds in the dwellings and new onset asthma, except for mouldy odour. By contrast, they found strong associations between prevalence of asthma and dampness or mould in the initial cross-sectional analysis at baseline. ${ }^{21}$ These differences indicate further need to analyse dampness/moulds in dwellings as a risk factor for new onset asthma in cohorts of different ages and in different climate zones, and using different asthma definitions.

A higher RR for new onset asthma was observed for those with multiple sensitisation at baseline, especially if they were sensitised to moulds. Totally $11.8 \%$ were sensitised to the moulds $C$ herbarum and/or $A$ alternata, two common moulds which can be 
found in the indoor environment. ${ }^{22} 23$ There are different possible mechanisms for respiratory effects of mould exposure. Fungi can be sources for allergens that can cause allergic asthma. It has been shown that mould allergy is related to severity of asthma, ${ }^{24}$ but subjects sensitised to mould are usually sensitised to many other allergens, making it difficult to isolate the effect of the mould allergy. Moreover, moulds may contain compounds which have inflammatory effects, for instance, $\beta-1-3$-glucans in the cell wall structure, ${ }^{25}$ and moulds can produce volatile organic compounds ${ }^{10}$ and mycotoxins ${ }^{26}$

Sex differences with respect to sensitivity to environmental exposure are an important issue. In general, men and women had similar responses to dampness and mould in our study, except for moulds in the living room, where women had a higher risk. The reason for a higher risk in women is unclear, but it could be that women generally spend more time in the home, and might more often do cleaning or other activities in the living room which could stir up settled dust containing fungal contaminants. There are few studies on sex differences in relation to mould and dampness exposure. One study from Canada suggests that women may be more susceptible to effects of dampness than men are. ${ }^{27}$

\section{CONCLUSION}

Dampness and indoor moulds in dwellings are related to an increased incidence of asthma in adults, The effect seems to be stronger in those with multiple sensitivity, and in those sensitised to moulds. About 5-15\% of adult onset asthma could be attributed to dampness-related exposure at home. There is a clear need for improvements of housing conditions in order to reduce the dampness-related exposure to counteract the increase of asthma in adults.

\footnotetext{
Author affiliations

${ }^{1}$ Department of Medical Sciences, Uppsala University, Uppsala, Sweden

${ }^{2}$ Centre for Research in Environmental Epidemiology (CREAL), Barcelona, Spain

${ }^{3}$ Municipal Institute of Medical Research (IMIM-Hospital del Mar), Barcelona, Spain

${ }^{4}$ CIBER Epidemiologia y Salud Publica, (CIBERESP), Barcelona, Spain

${ }^{5}$ Helmholtz Zentrum München, German Research Centre for Environmental Health, Institute of Epidemiology, Neuherberg, Germany

${ }^{6}$ Department of Occup. Med., Bergen respiratory Research Group, Institute of Medicine, University of Bergen, Haukeland University Hospital, Bergen, Norway ${ }_{7}^{7}$ Department of Experimental and Health Sciences, Pompeu Fabra University, (UFP), Barcelona, Spain

${ }^{8}$ Department of Epidemiology and Public Health, Tropical and Public Health Institute (Swiss TPH), Basel, Switzerland

${ }^{9}$ Department of Health Science, University of Pavia, Pavia, Italy

${ }^{10}$ Department of Occupational Medicine, University of Verona, Verona, Italy

${ }^{11}$ Department of Public Health, University of Tartu, Tartu, Estonia

${ }^{12}$ Archimedes Foundation, Research and Cooperation Centre, Tartu, Estonia

${ }^{13}$ Respiratory Epidemiology and Public Health Group, National Heart and Lung Institute, Imperial College, London, UK
}

Acknowledgements The coordination of the ECRHS II was supported by the European Commission, as part of their Quality of Life programme. The following bodies funded the local studies in ECRHS II included in this paper. Albacete: Fondo de Investigaciones Santarias (FIS) (grant code: 97/0035-01, 99/0034-01 and 99/ 0034-02), Hospital Universitario de Albacete, Consejeria de Sanidad. Antwerp: FWO (Fund for Scientific Research)-Flanders Belgium (grant code: G.0402.00), University of Antwerp, Flemish Health Ministry. Barcelona: SEPAR, Public Health Service (grant code: R01 HL62633-01), Fondo de Investigaciones Santarias (FIS) (grant code: 97/0035-01, 99/0034-01 and 99/0034-02) CIRIT (grant code: 1999SGR 00241) 'Instituto de Salud Carlos III' Red de Centros RCESP, C03/09 and Red RESPIRA, C03/011. Basel: Swiss National Science Foundation, Swiss Federal Office for Education and Science, Swiss National Accident Insurance Fund (SUVA). Bergen: Norwegian Research Council, Norwegian Asthma and Allergy Association (NAAF), Glaxo Wellcome AS, Norway Research Fund. Bordeaux: Institut Pneumologique d'Aquitaine. Erfurt: GSF-National Research Centre for Environment and Health, Deutsche Forschungsgemeinschaft (DFG) (grant code FR 1526/1-1). Galdakao: Basque Health Dept. Goteborg: Swedish Heart Lung Foundation, Swedish Foundation for Health Care Sciences and Allergy Research, Swedish Asthma and Allergy Foundation, Swedish Cancer and Allergy Foundation. Grenoble: Programme Hospitalier de Recherche Clinique-DRC de Grenoble 2000 no. 2610, Ministry of Health, Direction de la Recherche Clinique, Ministere de I'Emploi et de la Solidarite, Direction Generale de la Sante, CHU de Grenoble, Comite des Maladies Respiratoires de I'Isere. Hamburg: GSF-National Research Centre for Environment and Health, Deutsche Forschungsgemeinschaft (DFG) (grant code MA 711/4-1). Ipswich and Norwich: Asthma UK (formerly known as National Asthma Campaign (UK). Huelva: Fondo de Investigaciones Santarias (FIS) (grant code: 97/0035-01, 99/0034-01 and 99/0034-02). Montpellier: Programme Hospitalier de Recherche Clinique-DRC de Grenoble 2000 no. 2610, Ministry of Health, Direction de la Recherche Clinique, CHU de Grenoble, Ministere de l'Emploi et de la Solidarite, Direction Generale de la Sante, Aventis (France), Direction Régionale des Affaires Sanitaires et Sociales Languedoc-Roussillon. Oviedo: Fondo de Investigaciones Santarias (FIS) (grant code: 97/0035-01, 99/0034-01 and 99/0034-02). Paris: Ministere de l'Emploi et de la Solidarite, Direction Generale de la Sante, UCB-Pharma (France), Aventis (France), Glaxo France, Programme Hospitalier de Recherche Clinique-DRC de Grenoble 2000 no. 2610, Ministry of Health, Direction de la Recherche Clinique, CHU de Grenoble. Pavia: Glaxo-SmithKline Italy, Italian Ministry of University and Scientific and Technological Research (MURST), Local University Funding for research 1998 and 1999 (Pavia, Italy). Portland: American Lung Association of Oregon, Northwest Health Foundation, Collins Foundation, Merck Pharmaceutical. Reykjavik: Icelandic Research Council, Icelandic University Hospital Fund. Tartu: Estonian Science Foundation. Turin: ASL 4 Regione Piemonte (Italy), AO CTO/ICORMA Regione Piemonte (Italy), Ministero dell'Università e della Ricerca Scientifica (Italy), Glaxo Wellcome spa (Verona, Italy). Umeå: Swedish Heart Lung Foundation, Swedish Foundation for Health Care Sciences and Allergy Research, Swedish Asthma and Allergy Foundation, Swedish Cancer and Allergy Foundation. Uppsala: Swedish Heart Lung Foundation, Swedish Foundation for Health Care Sciences and Allergy Research, Swedish Asthma and Allergy Foundation, Swedish Cancer and Allergy Foundation. Verona: University of Verona. Italian Ministry of University and Scientific and Technological Research (MURST); Glaxo-Smith Kline Italy.

Contributors DN, JPZ, JH, CS, JS, NK, SV,MO, AS and DJ designed the study. EP managed and analysed the data. All authors participated in the interpretation and presentation of the results.

Competing interests None.

Patient consent Obtained

Ethics approval The Ethics Committee in each centre approved the study.

Provenance and peer review Not commissioned; externally peer reviewed.

\section{REFERENCES}

1 World Health Organization (WHO) Regional office for Europe. Guidelines for indoor air quality: dampness and mould. Copenhagen, Denmark: WHO Regional Office for Europe, 2009:1-228.

2 Bornehag C-G, Blomquist G, Gyntelberg F, et al. Dampness in buildings and Health (NORDDAMP). Indoor Air 2001;11:72-86.

3 Peat JK, Dickerson J, Li J. Effects of damp and mould in the home on respiratory health: a review of the literature. Allergy 1998;53:120-8.

4 Fisk WJ, Lei-Gomez Q, Mendell MJ. Meta-analysis of the associations of respiratory health effects with dampness and moulds in homes. Indoor Air 2007;17:284-96.

5 Gunnbjornsdottir Ml, Franklin KA, Norbäck D, et al. Prevalence and incidence of respiratory symptoms in relationship to indoor dampness: the RHINE study. Thorax 2006;61:221-5.

6 Jaakkola MS, Nordman H, Piipari R, et al. Indoor dampness and moulds and development of adult-onset asthma: a population-based case-control study. Environ Health Perspect 2002;110:543-7.

7 Zock JP, Jarvis D, Luczynska C, et al. Housing characteristics, reported mould exposure, and asthma in the European Community Respiratory health Survey. J Allergy Clin Immunol 2002;110:285-92.

8 Bush RK, Portnoy JM, Saxon A, et al. The medical effects of mold exposure. J Allergy Clin Immunol 2006;117:326-33.

9 Nevalainen A, Seuri M. Of microbes and men. Indoor Air 2005;15(Suppl 9):58-64.

10 Norbäck D, Wieslander G, Nordström K, et al. Asthma symptoms in relation to measured building dampness in the upper concrete floor construction, and 2-ethyl-1-hexanol in indoor air. Int J Tuberd Lung Dis 2000;4:1016-25.

11 Fisher $G$, Dott $W$. Relevance of airborne fungi and their secondary metabolites for environmental, occupational and indoor hygiene. Arch Microbiol 2003;179:75-82.

12 Burney PGJ, Luczynska CM, Chinn S, et al. The European Community Respiratory health survey. Eur Respir J 1994;7:954-960.

13 Janson C, Anto J, Burney P, et al. The European Community Respiratory Health Survey: what are the main results so far? Eur Respir J 2001;18:598-611.

14 Chinn S, Jarvis D, Burney $\mathrm{P}$, et al. Increase in diagnosed asthma but not in symptoms in the European Community Respiratory Health Survey. Thorax 2004;59:646-51

15 Norbäck D, Zock JP, Plana E, et al. Lung function decline in relation to mould and dampness in the home: the longitudinal European Community Respiratory Health Survey ECRHSII. Thorax 2011:66:396-401. 
16 Pekkanen J, Sunyer J, Chinn S. Nondifferential disease misclassification may bias incidence risk ratios away from the null. J Clin Epidemiol 2006;59:281-9.

17 Zock JP, Heinrich J, Jarvis D, et al. Indoor Working group of the European Community Respiratory Health Survey II. Distribution and determinants of house dust mite allergens in Europe: the European Community Respiratory Health Survey II. J Allergy Clin Immunol 2006;118:682-690.

18 Der Simonian R, Liard N. Meta-analysis in clinical trials. Control Clin Trials 1986;7:117-88.

19 Greenland S, Drescher K. Maximum likelihood estimation of the attributable fraction from logistic models. Biometrics 1993;49:865-72.

20 Verlato G, Calabrese R, De Marco R. Correlation between asthma and climate in the European respiratory Health Survey. Arch Environ Health 2002;57:48-52.

21 Larsson M, Hägerhed-Engman L, Moniruzzaman S, et al. Can we trust cross-sectional studies when studying the risk of moisture-related problems indoo for asthma in children? Int J Environ Health Res 2011;21:237-47.
22 Koch A, Heilemann KJ, Bischof W, et al. Indoor viable mold spores: a comparison between two cities. Erfurt (eastern Germany) and Hamburg (western Germany). Allergy 2000;55:176-80.

23 Garrett MH, Rayment PR, Hooper MA, et al. Indoor airborne fungal spores, house dampness and associations with environmental factors and respiratory health in children. Clin Exp Allergy 1998;28:459-67.

24 Zureik M, Neukirch C, Leynaert B, et al. Sensitisation to airborne moulds and severity of asthma: cross sectional study from European Community respiratory health survey. BMJ 2002;325:411-14.

25 Douwes J. (1->3)-Beta-D-glucans and respiratory health: a review of the scientific evidence. Indoor Air 2005;15:160-69.

26 Robbins CA, Swensson LJ, Nealley ML, et al. Health effects of mycotoxins in indoor air: a critical review. Appl Occup Environ Hyg 2000;15:773-84.

27 Rennie D, Chen Y, Lawson J, et al. Different effect of damp housing on respiratory health in women. J Am Med Womens Assoc 2005;60:46-51. 